\title{
Sub-micron lines patterning into silica using water developable chitosan bioresist films for eco-friendly positive tone e-beam and UV lithography
}

Mathieu Caillau ${ }^{1}$, Céline Chevalier ${ }^{2}$, Pierre Crémillieu ${ }^{1}$, Thierry Delair ${ }^{3}$, Olivier Soppera ${ }^{4}$, Benjamin Leuschel $^{4}$, Cédric Ray ${ }^{5}$, Christophe Moulin ${ }^{5}$, Christian Jonin ${ }^{5}$, Emmanuel Benichou, Pierre-François Brevet $^{5}$, Christelle Yeromonahos ${ }^{1}$, Emmanuelle Laurenceau ${ }^{1}$, Yann Chevolot* ${ }^{1}$, Jean-Louis Leclercq* ${ }^{1}$

${ }^{1}$ Université de Lyon 1, Ecole Centrale de Lyon, UMR-CNRS 5270, Institut des Nanotechnologies de Lyon, F-69134, Ecully, France

${ }^{2}$ Université de Lyon 1, INSA Lyon, UMR-CNRS 5270, Institut des Nanotechnologies de Lyon, F69621, Villeurbanne, France

${ }^{3}$ Université de Lyon 1, Polytech, UMR-CNRS 5223, Ingénierie des Matériaux Polymères, F-69622, Villeurbanne

${ }^{4}$ Université de Haute Alsace, UMR-CNRS 7361, Institut de Science des Matériaux de Mulhouse, F68057, Mulhouse, France

${ }^{5}$ Université de Lyon 1, Université Claude Bernard Lyon 1, UMR-CNRS 5306, Institut Lumière Matière, F-69622, Villeurbanne, France

*Corresponding authors: yann.chevolot@ec-lyon.fr ; jean-louis.leclercq@ec-lyon.fr

\begin{abstract}
Biopolymers represent natural, renewable and abundant materials. Their use is steadily growing in various areas (food, health, building ...) but, in lithography, despite some works, resists, solvents and developers are still oil-based and hazardous chemicals. In this work, we replaced synthetic resist by chitosan, a natural, abundant and hydrophilic polysaccharide. High resolution sub-micron patterns were obtained through chitosan films as water developable, chemically unmodified, positive tone mask resist for an eco-friendly electron beam and deep-UV (193 nm) lithography process. Sub-micron patterns were also successfully obtained using a $248 \mathrm{~nm}$ photomasker thanks to the addition of biosourced photoactivator, riboflavin. Patterns were then transferred by plasma etching into silica even for high resolution patterns.
\end{abstract}

Keywords: chitosan, riboflavin, water developable, biopolymer, environmentally-friendly, photolithography, electron beam lithography, etching, green nanotechnology, green-tech 


\section{INTRODUCTION}

Environmentally-friendly processes are more and more adopted in chemistry ${ }^{1,2}$ and in nanotechnology ${ }^{3,4}$. In microelectronics industry, efforts have already been undertaken to reduce the environmental impact of technology in particular the one of lithography. Indeed, lithography requires oil based chemicals like solvents, resists and developers. These chemicals and theirs syntheses may be hazardous for health and environment generating security and waste management issues and costs. First efforts focused on changing the solvents by harmless ones such as ethyl lactate ${ }^{5}$. Some researchers went further by replacing the current resists by biosourced polymers soluble in aqueous solutions. Takei $e$ t al. used derivatives of polysaccharides as negative tone resist for electron beam (e-beam) lithography ${ }^{6-9}$ or for extreme ultra-violet (EUV) lithography ${ }^{9}$ whereas Kim et al. tested silk as positive and negative tone resists for e-beam ${ }^{10}$ or EUV lithography ${ }^{11}$. The polysaccharides of Takei et al. were chemically modified with acryloyl groups. In addition, although they could achieve high resolution with $50 \mathrm{~nm}$ lines spaced by $450 \mathrm{~nm}$, the selectivity of the chemically modified polysaccharides to fluorinated plasma etching was low. Therefore, a three layers process (resist, synthetic hard mask and synthetic etching layer) was required to enable transfer. With silk, although high resolution was also achieved (30 nm lines spaced by $100 \mathrm{~nm}$ for e-beam), selectivity to etching was not reported. Recently, a third group proposed egg white directly extracted from eggs as a resist ${ }^{12}$. But stripping of this resist was time consuming as the sample needed to be immersed in a solution of trypsin during $15 \mathrm{~h}$ which is not suited to a microelectronic process.

Herein, we proposed to replace current resists by another biopolymer, which is chitosan, for lithography and etching process as displayed in Figure 1.

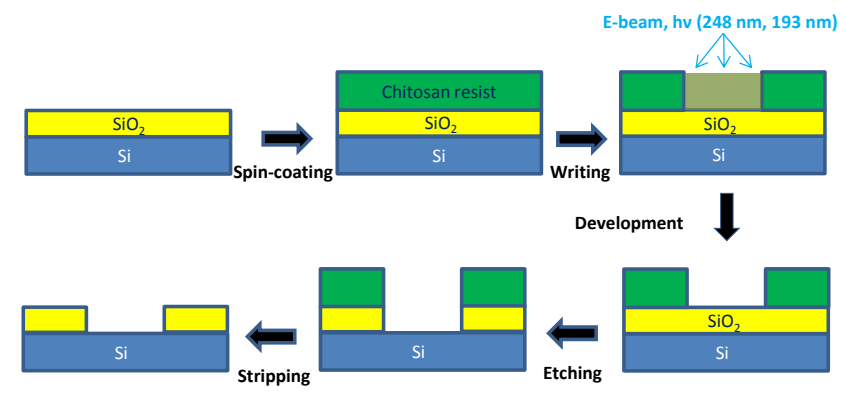

Figure 1 : Lithography and etching process applied on the chitosan bioresist film.

Chitosan is a polysaccharide constituted of D-glucosamine and $N$-acetyl-D-glucosamine units. The number of $N$-acetylD-glucosamine units along a chain corresponds to the degree of acetylation (DA, in percentage). Chitosan is prepared from chitin, the $N$-acetyl-D-glucosamine polysaccharide ${ }^{13}(\mathrm{DA}=100 \%)$. This polymer is the second most abundant on Earth after cellulose. It is present in the exoskeleton of arthropods and industrially extracted from the waste from sea food industry as crabs and shrimps shells. Chitosan is also a biodegradable, biocompatible and non-toxic polymer. Due to these properties, it was already used in biotechnology as an adhesion film for the cell culture ${ }^{14-16}$. Recent works used chitosan as positive tone resist for e-beam lithography ${ }^{17,18}$. Patterns of holes of $500 \mathrm{~nm}$ spaced by $1.5 \mu \mathrm{m}$ with development in water have been realized but no transfer of these patterns into the underlying substrate was reported. We demonstrated that unmodified chitosan could be used as a positive tone resist in a complete lithography/ etching process, using $30 \mathrm{kV}$ e-beam lithography. $50 \mathrm{~nm}$ patterns were obtained and transferred by plasma etching into silica layer using a completely free organic solvent process ${ }^{19}$. The chitosan film resistance to etching by $\mathrm{CHF}_{3}$ plasma was assessed through its selectivity corresponding to the ratio between etching rate of silica on etching rate of chitosan. The selectivity was more than 4.25 and appeared slightly higher than the resistance of PMMA (950-PMMA-A4 from Microchem) which is a common resist in lithography ${ }^{19}$. 
In this work, we aim to demonstrate that the unmodified chitosan can be a universal green resist for lithography (e-beam and UV) allowing sub-micron resolution with possibility of transfer into a silica layer.

\section{EXPERIMENTAL}

\subsection{Materials}

Highly deacetylated chitosan was provided by Mahtani Chitosan PVT, Ltd (India) from squid pens and further purified according to the procedure of Rinaudo ${ }^{13}$. Its molar mass of $570 \mathrm{~kg} \cdot \mathrm{mol}^{-1}$ was measured by size exclusion chromatography. Chitosans of DA of $2 \%$ and $35 \%$ were then prepared. DA was quantified by ${ }^{1} \mathrm{H}$ NMR using an AVANCE III $400 \mathrm{MHz}$ spectrometer. Deionized water (ultrapure, $18 \mathrm{M} \Omega$ ) and acetic acid (Fluka Analytical, glacial acetic acid) were used. Chitosan films were deposited on silica/ silicon substrates using classical spin-on technology. The silica layer (90 nm or $200 \mathrm{~nm}$ ) was obtained by plasma enhanced chemical vapour deposition. In the case of photolithography at $248 \mathrm{~nm}$, a natural dye, riboflavin (Sigma-Aldrich, > $98 \%$, extracted from Ermothycium ashbyii), was added in the chitosan solution.

\subsection{Methods for chitosan film preparation and characterizations}

Aqueous diluted acetic acid solution was used to dissolve solid chitosan at concentration of $0.7 \%$ (w/v) or $0.9 \%$ (w/v), depending on the desired thickness. Acetic acid was stoichiometrically added with respect to the free amines of the glucosamine residues. Chitosan films were prepared on silica/silicon substrates by $30 \mathrm{~s}$ of spin-coating at $5000{\mathrm{rd} . \mathrm{min}^{-1}}^{-1}$ and $3000 \mathrm{rd} . \mathrm{s}^{-2}$ followed by a softbake at $100{ }^{\circ} \mathrm{C}$ for $1 \mathrm{~min}$ on a hotplate. It is well known that chitosan through hydrogen bonds have a strong adhesion on silica and silicon surfaces thanks to surface $\mathrm{SiOH}$ groups ${ }^{20}$.

Film thickness was measured by ellipsometry with a spectroscopic ellipsometer UVISEL тм from Horiba using the classical formula dispersion as model in the Horiba software. The model was adapted to chitosan by adjusting the refractive index between $1.5-1.6$ and the extinction coefficient to 0 at $630 \mathrm{~nm}^{21}$.

X-ray reflectivity was performed on an X-ray diffractometer from SmartLab using the K $\alpha 1$ copper ray to determine the chitosan films density.

For photolithography at $248 \mathrm{~nm}$, riboflavin was added in the chitosan $(0.9 \%(\mathrm{w} / \mathrm{v}))$ solution at a concentration of $2.2 \mathrm{x}$ $10^{-4}$ mol.L $\mathrm{L}^{-1}$, maximum of riboflavin solubility in our conditions. Chitosan-riboflavin films were deposited on silicasilicon substrates following the same protocol as previously described.

In order to determine the distribution of riboflavin in the chitosan films, Two Photon Emission Fluorescence (TPEF) measurements (non-linear optic measurements) were carried out at Institut Lumière Matière. The non-linear optic experimental setup was based on a frequency doubled femtosecond Er-doped fiber laser source (Menlo Lasers, C-Fiber 780). The laser provided pulses with a duration of about $100 \mathrm{fs}$ at a repetition rate of $100 \mathrm{MHz}$. The fundamental wavelength was set at $780 \mathrm{~nm}$ (spectral width of $13 \mathrm{~nm}$ ) and an average power of about $65 \mathrm{~mW}$ was measured at the laser exit. The light beam was focused by a standard microscope objective (magnification X20, NA 0.75) mounted onto a microscope stand (Nikon Eclipse TE2000-U with 3D positioning in inverted geometry) holding the sample. Galvanometric mirrors allowed a beam swept to acquire non-linear images of various samples. The nonlinear optical signals, TPEF, were collected into an optical fiber feeding a spectrometer after going through mirrors and various color filters. These filters were placed on the emission light beam path to avoid any unwanted fundamental. A cooled photomultiplier tube was placed after the spectrometer. 


\subsection{Lithography and development}

E-beam lithography was performed at $100 \mathrm{kV}$ on an e-beam Writer JEOL JBX-9300FS with a ZrO/W thermal field emission source was used at the Plateforme Technologique Amont (PTA) in Grenoble. For $100 \mathrm{kV}$ accelerating voltage, the electron beam has a diameter Gaussian spot of $4 \mathrm{~nm}$, a speed of $50 \mathrm{MHz}$ for a current range of $50 \mathrm{pA}-100 \mathrm{nA}$.

Photolithography at $193 \mathrm{~nm}$ was performed at the Institut de Science des Matériaux de Mulhouse with a home-made DUV interferometric setup using a $193 \mathrm{~nm}$ ArF laser (Braggstar from Coherent) and phase masks generating regular sinusoidal patterns with periods ranging from $100 \mathrm{~nm}$ to $600 \mathrm{~nm}$.

Photolithography at $248 \mathrm{~nm}$ was performed at PTA on a MBJB4 DUV SUSS Micro Tec device with a density power of $4 \mathrm{~mW} \cdot \mathrm{cm}^{-2}$ and a lamp power of $500 \mathrm{~W}$.

Lithography is followed by development in deionized water $(18 \mathrm{M} \Omega)$ during $60 \mathrm{~s}$.

\subsection{Etching process}

Etching selectivity study of chitosan films was carried out in a Reactive Ion Etcher (RIE) Corial $200 \mathrm{~S}$ using $\mathrm{CHF}_{3}$ gas reactant (usually used for silica etching) during $2 \mathrm{~min}$ under $100 \mathrm{sccm}$ of $\mathrm{CHF}_{3}$ at a pressure of $50 \mathrm{mTorr}$ at $20^{\circ} \mathrm{C}$ for a power of $140 \mathrm{~W}$ (corresponding to a bias voltage of $590 \mathrm{~V}$ ). Chitosan was, then, selectively removed by $\mathrm{O}_{2}$ plasma for 1 min under $100 \mathrm{sccm}$ of $\mathrm{O}_{2}$ at $100 \mathrm{mTorr}, 20^{\circ} \mathrm{C}, 100 \mathrm{~W}$ and bias voltage of $460 \mathrm{~V}$.

\subsection{Patterns characterizations}

Patterns observations were realized by scanning electron microscopy (SEM) on a scanning electron microscope JEOL JSM $7401 \mathrm{~F}$ at $2 \mathrm{kV}, 5 \mu \mathrm{A}$ and a working distance of $4 \mathrm{~mm}$. The Image $\mathbf{J}$ software was used for the analysis of the SEM images to measure the size of the patterns.

The AFM characterization was carried out with a PicoPlus AFM from Molecular Imaging, in resonant mode.

\subsection{UV-visible spectroscopy}

The absorbance of the chitosan resist solutions for photolithography was measured by a SAFAS UVmc2 double beam spectrometer with quartz cuvettes of $1 \mathrm{~cm}$. The blank was realized with an aqueous solution of acetic acid $\left(0.05\right.$ mol.L $\left.{ }^{-1}\right)$ in a quartz cuvette.

The absorbance of the chitosan film was measured by a Cary 5G UV-vis-NI spectrophotometer with 2 reflexions at $45^{\circ}$. Data were treated with the Scan software to obtain the film absorbance.

\section{RESULTS AND DISCUSSION}

\subsection{Film properties}

In the introduction, the selectivity of chitosan resist to plasma etching was already presented. We previously demonstrated that chitosan films were stable at temperature up to $200{ }^{\circ} \mathrm{C}$ and were stable during development in water ${ }^{19}$. Herein, we will discuss particularly about the absorbance of the film for the photolithographic aspect and their thickness. 
For photolithography, it is of prime importance that the resist can absorb the energy of the wavelength to generate chemical reactions. The absorbance of a chitosan (DA $2 \%$ ) film was measured as displayed in Figure 2.

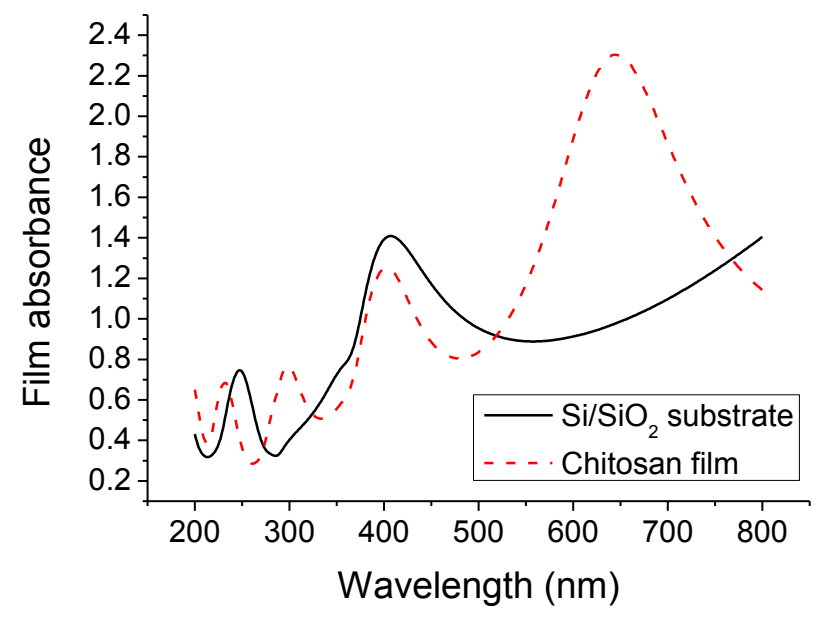

Figure 2: Chitosan film absorbance (thickness of $180 \mathrm{~nm}$ ). Substrate absorbance is given as reference.

On Figure 2, some interference fringes can be seen but the chitosan film absorbance is very low particularly at $248 \mathrm{~nm}$ corresponding to the wavelength of the photomasker we used. The low absorbance at this wavelength is confirmed for chitosan in solution for chitosan of low DA (2\%) but also at high DA (35\%) as displayed in Figure 3. This figure corresponds to the chitosan absorbance spectrum in solution for a concentration of $0.9 \%(\mathrm{w} / \mathrm{v})$. On the contrary, it seems that, for photolithography at $193 \mathrm{~nm}$, chitosan absorbance in solution is higher than at $248 \mathrm{~nm}$. Indeed, at $193 \mathrm{~nm}$, absorbance is of 1.6 .

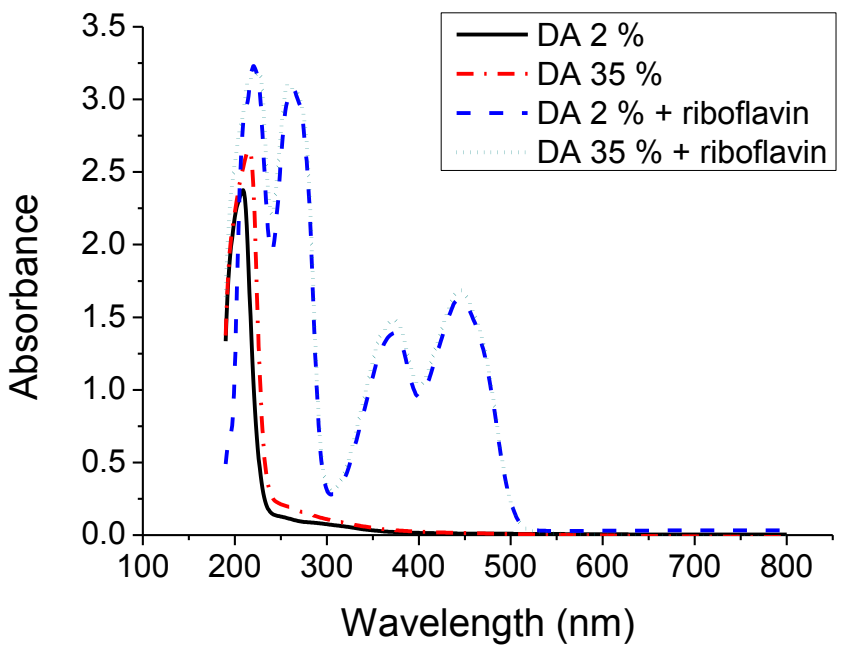

Figure 3: UV-visible spectra of a solution of chitosan of DA $=2$ and $35 \%$ concentrated at $0.9 \%(\mathrm{w} / \mathrm{v})$ in deionized water and acetic acid $\left(0.05\right.$ mol. $\left.\mathrm{L}^{-1}\right)$ solutions with and without riboflavin (concentrated at $2.2 \times 10^{-4}$ mol. $\left.\mathrm{L}^{-1}\right)$. Blank was made in a quartz cuvette with an aqueous acetic acid solution $\left(0.05 \mathrm{~mol} . \mathrm{L}^{-1}\right)$.

In order to improve chitosan absorbance and so chitosan photosensitivity, a natural dye, riboflavin or $\mathrm{B}_{2}$ vitamin, was added in the formulation of the resists. It is a natural and hydrosoluble dye present in fruits, vegetables and animals ${ }^{22}$ and extracted from flavinogenic microorganisms ${ }^{23}$. It is known to generate the photodegradation of organic compounds 
(pesticides, food ...) under UV-visible light ${ }^{24}$. Riboflavin was added at the concentration of $2.2 \times 10^{-4} \mathrm{~mol}^{-\mathrm{L}^{-1}}$ corresponding to its maximum solubility in deionized water in our conditions. At $248 \mathrm{~nm}$, the optical absorption of the chitosan- riboflavin resist solution was significantly increased (Figure 3). Indeed the absorbance of the solution was of 2.5 with riboflavin whatever the chitosan DA and only of 0.25 without riboflavin.

The addition of riboflavin being required for photolithography at $248 \mathrm{~nm}$, we studied the effect of its presence in the film particularly the possibility to make a film and its distribution into this film. Chitosan- riboflavin films were deposited by spin-coating at $3000 \mathrm{rd} \cdot \mathrm{s}^{-2}$ for $30 \mathrm{~s}$ followed by a softbake at $100{ }^{\circ} \mathrm{C}$ for $1 \mathrm{~min}$. Chitosan of DA $2 \%$ and $35 \%$ were tested for two concentrations. The film thickness as a function of the DA for two concentrations $(0.7 \%$ and $0.9 \%(w / v))$ is displayed in Figure 4. Film thicknesses are shown for chitosan with riboflavin $\left(2.2 \times 10^{-4} \mathrm{~mol}^{-1} \mathrm{~L}^{-1}\right)$ and without it.

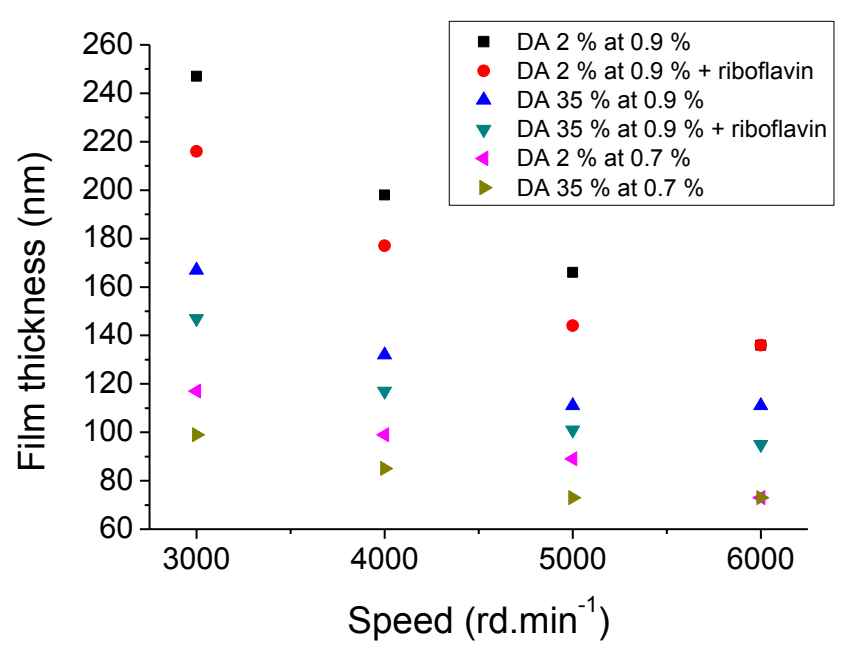

Figure 4 : Spin-curves for chitosan bioresists for two DA $(2 \%$ and $35 \%)$ and two concentrations $(0.9 \%$ and $0.7 \%$ (w/v)) with or without riboflavin.

Chitosan- riboflavin films could be obtained by spin-coating. The spin-curves on Figure 4 for chitosan - riboflavin films present the same profile and similar thickness than those obtained with chitosan alone. With or without riboflavin, the film thickness depends on the concentration of the polymer as expected but also on the DA. Indeed, spin-coated film thickness depends on inverse of the square of the dynamic viscosity of the polymer solution ${ }^{25}$. This viscosity relies on the quality of the solvent to dissolve the polymer and to the concentration of polymer. When a polymer is dissolved in a good solvent, its chains are completely spread leading to an increase in the viscosity ${ }^{26}$. In the case of low DA chitosan in an acidic solution, the chains were totally protonated. They could spread easily. At higher DA, less amino groups were protonated. Even though $\mathrm{N}$-acetyl group is polar, the solvent quality, under similar conditions, decreased reducing the chitosan solubility as observed by Rinaudo $\mathrm{et} \mathrm{al} .{ }^{27}$, Anthonsen $\mathrm{et} \mathrm{al} .^{28}$ and Wang $\mathrm{et} \mathrm{al} .^{29}$. Chains were less spread and the viscosity was consequently lowered. Therefore, viscosity and the film thickness decreased from low DA to high DA as we noticed. The increase in thickness with concentration could be explained, according to Rinaudo et al. ${ }^{27}$, by the fact that, at these concentrations and in these conditions, chitosan could be assumed in a semi-diluted concentration. Chitosan chains would then be very close ones to others generating entanglements which would limit the flow. The higher the concentration, the higher the number of entanglements, hence the increase in viscosity and in film thickness.

In order to determine if riboflavin was homogeneously distributed in a chitosan film, chitosan -riboflavin films deposited by spin-coating on the silica- silicon substrate were analysed by a non-linear optic measurement Two Photon Excited 
Fluorescence (TPEF). For a maximal efficiency of riboflavin, it was of prime importance that riboflavin repartition was well distributed in the film. The TPEF measurements gave us access to a three-dimensional resolution. Indeed, the material was excited by two synchronous photons, thus the non-linear optical process only occurred at the focus of the beam. Firstly, TPEF spectra for a chitosan film and a riboflavin-chitosan film with a $780 \mathrm{~nm}$ wavelength excitation were recorded (Figure 5).

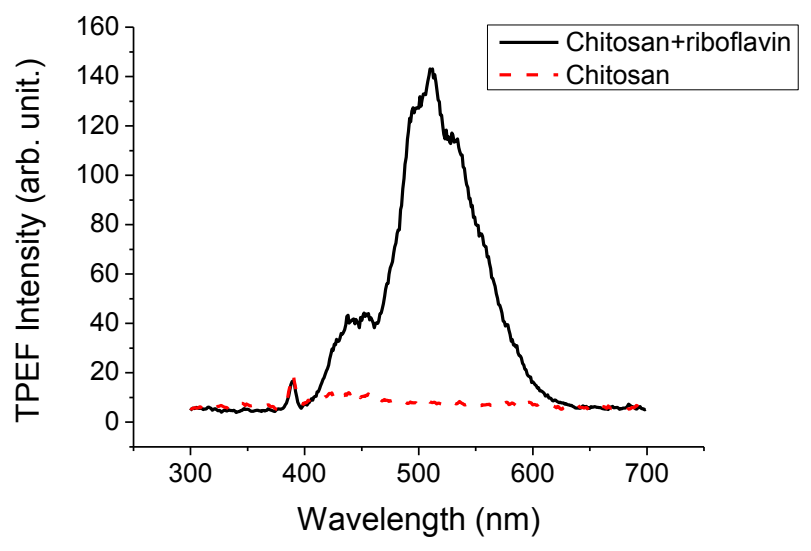

Figure 5 : TPEF spectra for a pure chitosan film and a mixed riboflavin-chitosan film with a $780 \mathrm{~nm}$ wavelength excitation.

In both cases, a peak of the half of the $780 \mathrm{~nm}$ excitation wavelength is observed on Figure 5 corresponding to a second harmonic response of these two films due to chitosan. We noticed that chitosan alone was not fluorescent. On the contrary chitosan-riboflavin film presented a high TPEF intensity centred at $512 \mathrm{~nm}$. Thus this fluorescence was only due to riboflavin.

TPEF signal integrated over the $410-650 \mathrm{~nm}$ spectral region as a function of the film depth was then recorded (Figure $6)$.

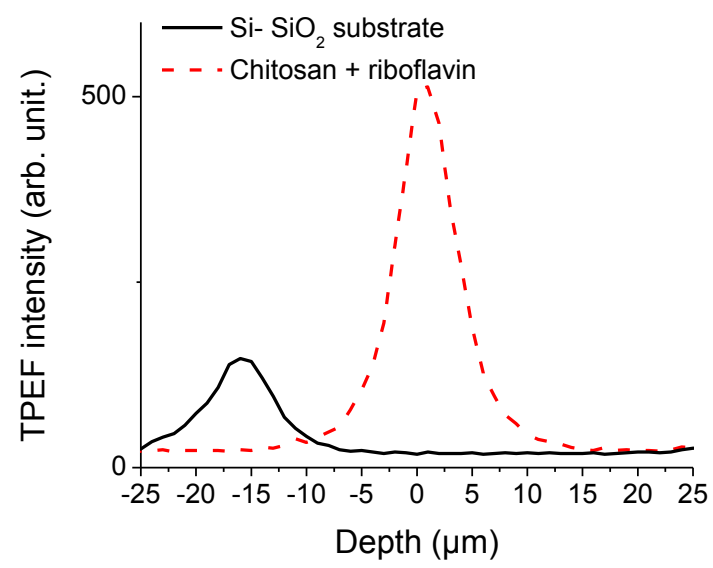

Figure 6 : TPEF signal integrated over the 410 - $650 \mathrm{~nm}$ spectral region as a function of the film depth for chitosan + riboflavin film and the reference $\left(\mathrm{SiO}_{2}\right.$ layer on $\mathrm{Si}$ substrate).

According to the previous TPEF spectra, the TPEF signal was only due to riboflavin. On the Figure 6, a TPEF peak appears in the region focused on the chitosan -riboflavin layer (thickness of $150 \mathrm{~nm}$ ). The reference corresponding to the $\mathrm{SiO}_{2}$ layer on silicon substrate was obtained in absence of chitosan and riboflavin and was shifted due to a different position of the sample. This depth profile measurement resulted from the convolution of the beam focus and the film 
depth. Hence a TPEF maximum indicated that at the resolution imposed by the beam waist (few micrometers), riboflavin was distributed rather homogeneously within the film.

According to these studies, riboflavin enhanced the chitosan photosensitivity for photolithography at $248 \mathrm{~nm}$ and is homogeneously distributed in the chitosan film.

The following parts of this work will now focused on the results obtained in lithography (e-beam, $248 \mathrm{~nm}$ and $193 \mathrm{~nm}$ ) and in transfer with this bioresist.

\subsection{Electron beam lithography}

Firstly, Monte- Carlo simulations were undertaken to simulate the behaviour of electrons through a chitosan film deposited on a silicon substrate with a silica layer of $90 \mathrm{~nm}$. The results were then compared to the ones for a PMMA film (70 nm in the experimental conditions for 950-PMMA-A4 from Microchem). Results are displayed in the Figure 7. Simulations were realized on the CASINO software for an electron beam with a diameter of $10 \mathrm{~nm}$ for 200 electrons accelerated at $100 \mathrm{kV}$. Density of the different material was 0.88 for chitosan for DA $2 \%$ measured by X-ray reflectometry and already registered in the database 1.74 for silica, 2.33 for silicon and 1.18 for PMMA densities.

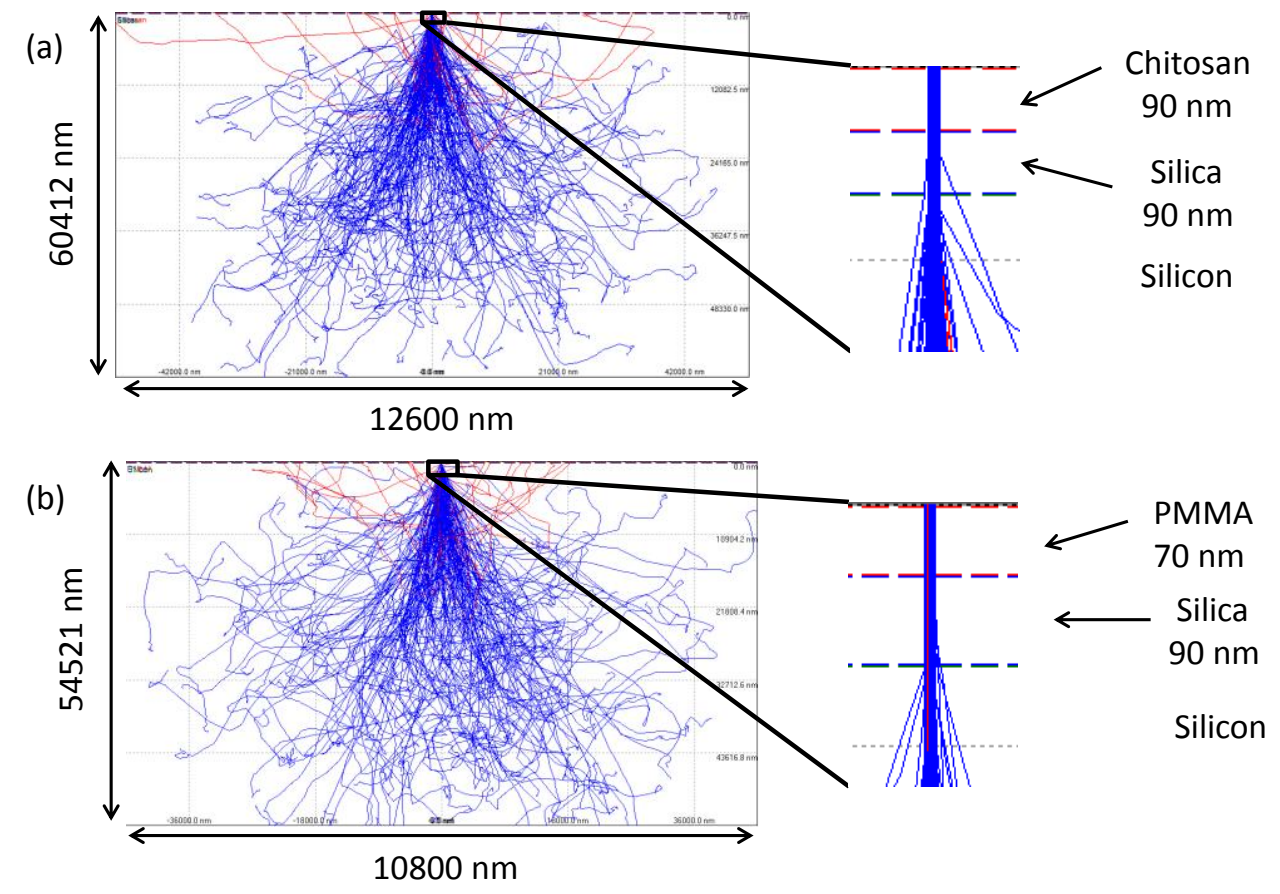

Figure 7 : Monte- Carlo simulations of the trajectory of 200 electrons at $100 \mathrm{kV}$ for a sample of resist (a) chitosan or (b) PMMA on silica and silicon. Primary electrons are in blue, backscattered electrons are in red.

Profile obtained for PMMA is similar to the one obtained for a $500 \mathrm{~nm}$ layer of PMMA by Urbánek et al. ${ }^{30}$ with the CASINO software. In both case, the electron beam passes through the polymer layer without any scattering. Back scattering took place randomly from the silicon substrate for around $10 \%$ of electrons. These simulations suggested that chitosan could behave as PMMA under an electron beam and validated the use of chitosan as resist for e-beam lithography. 
For electron beam lithography, we used chitosan of DA of $2 \%$ concentrated at $0.7 \%(\mathrm{w} / \mathrm{v})$ on silicon substrate with a silica layer of $90 \mathrm{~nm}$. The film thickness in these conditions was of $80-90 \mathrm{~nm}$. Development was performed in deionized water during $60 \mathrm{~s}$.

At previous studies with our $30 \mathrm{kV}$ e-beam writer, we demonstrated that high resolution patterns were obtained in a chitosan film with $50 \mathrm{~nm}$ lines spaced by $300 \mathrm{~nm}$ or $500 \mathrm{~nm}^{19}$. Line edge roughness was low in both cases, respectively of $19 \mathrm{~nm}$ and $14 \mathrm{~nm}$. In comparison, Voznesenskiy et al. ${ }^{17,18}$ who also worked on chitosan films in e-beam lithography ( $25 \mathrm{kV}$, deionized water as developer) obtained $500 \mathrm{~nm}$ holes spaced by $1.5 \mu \mathrm{m}$. At this point, we went further by increasing the resolution and demonstrating the high quality of the final patterns. Such resolution is similar at the one obtained by Takei et al. ${ }^{6}$ but for a lower electron energy than in their case $(75 \mathrm{kV})$ and for an unmodified biopolymer.

In order to validate chitosan as e-beam resists, next studies were performed with a $100 \mathrm{kV}$ standard e-beam writer. Submicronic $2 \mathrm{D}$ holes (Figure $8 \mathrm{a}$ ) and $1 \mathrm{D}$ lines (Figure $8 \mathrm{~b}$ ) patterns were patterned at $200 \mu \mathrm{C} . \mathrm{cm}^{-2}$ at $100 \mathrm{kV}$. Figure $8 \mathrm{a}$ and $\mathrm{b}$ show the preliminary results after development in deionized water. Holes and lines of $30 \mathrm{~nm}$ spaced by $200 \mathrm{~nm}$ were obtained. There are well consistent to the results obtained by Kim et al. ${ }^{10}$ who have patterned $30 \mathrm{~nm}$ holes spaced by $100 \mathrm{~nm}$ with an e-beam writer at $125 \mathrm{kV}$. Next work will focus on the optimization of exposure dose.
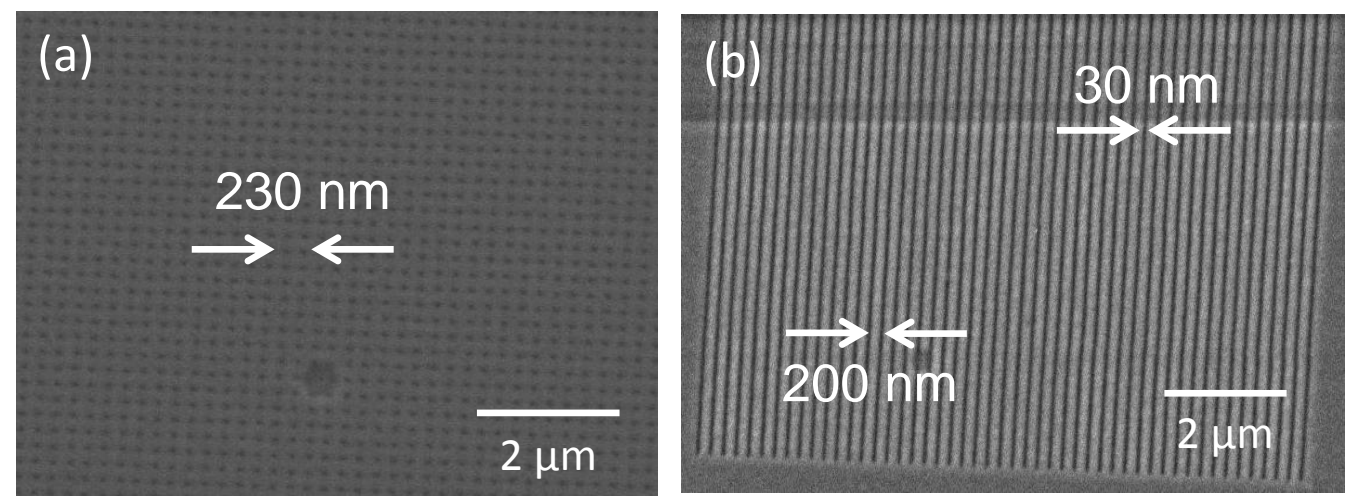

Figure 8 : SEM images of patterns obtained in a chitosan bioresist by e-beam lithography $\left(100 \mathrm{kV}, 200 \mu \mathrm{C} . \mathrm{cm}^{-2}\right)$ and development in deionized water (1 min) (a) $30 \mathrm{~nm}$ holes spaced by $200 \mathrm{~nm}$ and (b) $30 \mathrm{~nm}$ lines spaced by $200 \mathrm{~nm}$.

\subsection{Photolithography at $248 \mathrm{~nm}$}

UV light at $248 \mathrm{~nm}$ irradiation of chitosan was reported to generate the chitosan degradation by a free radical photooxidation mechanism ${ }^{31,32}$. But degradation could occur only for high doses of exposure $(2 \mathrm{~h}$ to $8 \mathrm{~h}$ at $248 \mathrm{~nm}$ with a dose density of $0.263 \mathrm{~J} . \mathrm{cm}^{-2} \cdot \mathrm{min}^{-1}$ ) as presented by Sionkowska et al. ${ }^{33}$. Indeed, as demonstrated in section 3.1 film properties, the adsorption of chitosan (DA $35 \%$, film thickness $90 \mathrm{~nm}$ prepared from a solution concentrated at $0.9 \%$ (w/v)) at 248 $\mathrm{nm}$ is low. We assessed that 50 minutes exposure $\left(11988 \mathrm{~mJ} . \mathrm{cm}^{-2}\right)$ was not sufficient to develop the patterns throughout the chitosan layer: only $10 \mathrm{~nm}$ thickness of the exposed area could be dissolved. Given these results and the low absorbance of the film, the addition of a photoactive agent, riboflavin, in the chitosan resist appears of interest. For the two chitosans with riboflavin (films prepared from a solution concentrated at $0.9 \%(\mathrm{w} / \mathrm{v})$ in chitosan and $2.2 \times 10^{-4}$ mol. $\mathrm{L}^{-1}$ in riboflavin), patterns were obtained with high quality. For DA $2 \%$, a dose of $10800 \mathrm{~mJ}^{\mathrm{c}} \mathrm{cm}^{-2}$ enabled to reveal patterns but only on the top surface $(10 \mathrm{~nm})$ of the chitosan film. On the contrary, using a DA $35 \%$, for the same dose of $10800 \mathrm{~mJ} . \mathrm{cm}^{-2}$, the patterns were reproduced into the whole thickness of chitosan film (Figure 9) with high fidelity to the mask. 

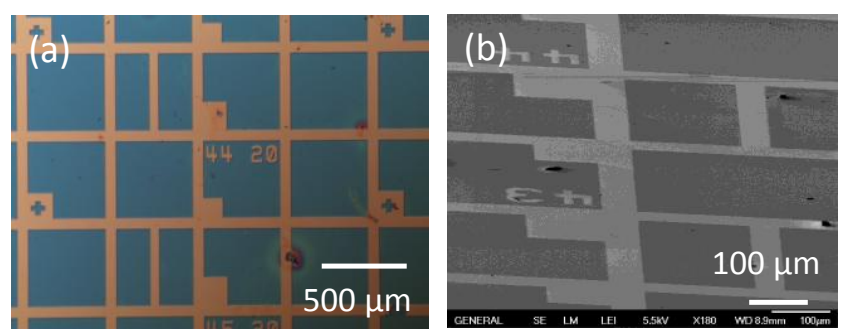

Figure 9 : (a) Optical and (b) SEM images of the patterns after lithography at $248 \mathrm{~nm}(10800 \mathrm{~mJ} . \mathrm{cm}-2)$ and development in deionized water for $1 \mathrm{~min}$. Patterns of the mask are non-exposed squares of $440 \mu \mathrm{m}$ x $440 \mu \mathrm{m}$ spaced of $60 \mu \mathrm{m}$ exposed lines.

DA appeared to have a significant effect on the photosensitivity at $248 \mathrm{~nm}$. At DA $2 \%$ or $35 \%$, patterns were revealed but at $35 \%$, riboflavin efficiency was dramatically increased. In both cases, photodegradation took place partly due to the exposure at the $248 \mathrm{~nm}$ as demonstrated by Sionkowska et al. ${ }^{33}$ and Wasikiewicz et al. ${ }^{32}$. At this effect, we can add the photodegradation caused by riboflavin. Under UV light, riboflavin is known to be excited which allowed the formation of reactive oxygen species (ROS) as $\mathrm{O}_{2}$ in excited singlet or triplet state, $\mathrm{O}_{2}{ }^{-}$or $\mathrm{H}_{2} \mathrm{O}_{2}{ }^{24,34}$. These $\mathrm{ROS}$ can react with chitosan by radical reactions to break the glycosidic bond. Given that the apparent increase of photoefficiency for DA $35 \%$, an additional possible mechanism can also occur since for a polymer with $\mathrm{C}=\mathrm{O}$ group in presence of another molecule or polymer with $\mathrm{C}=\mathrm{O}$ group, a vibrational mixing between these $\mathrm{C}=\mathrm{O}$ groups can be observed ${ }^{35}$. When the molecule was excited, an energy transfer could take place through this mixing leading to the excitation of the first polymer and, eventually, to its photodegradation. As chitosan at DA $35 \%$ has more $\mathrm{C}=\mathrm{O}$ groups than at DA $2 \%$ and as riboflavin also has $\mathrm{C}=\mathrm{O}$ groups, such mechanism could occur and explain this improvement of efficiency with DA $35 \%$.

On these bases, the study was pursued by increasing the resolution using mask with patterns of less than $0.3 \mu \mathrm{m}$. Results are displayed on the Figure 10 after development.

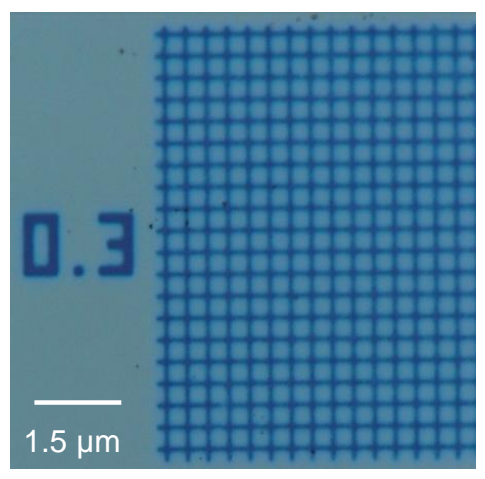

Figure 10 : Optical image of $0.3 \mu \mathrm{m}$ patterns obtained in a chitosan DA $35 \%$ - riboflavin film by photolithography at $248 \mathrm{~nm}(6400$ $\mathrm{mJ} . \mathrm{cm}^{-2}$ ) and revealed by development in deionized water during $1 \mathrm{~min}$.

As for e-beam lithography, it was possible to write sub-micronic patterns into a chitosan-riboflavin film. These preliminary results are very encouraging. However, the photosensitivity should be improved in order to reduce the exposure time.

\subsection{Photolithography at $193 \mathrm{~nm}$}


In photolithography at $193 \mathrm{~nm}$, the two chitosans (low DA at $2 \%$ and high DA at $35 \%$ ) were tested. The same chitosan films than for e-beam lithography (chitosan concentrated at $0.7 \%(\mathrm{w} / \mathrm{v})$ ) were tested with DUV doses ranging from 100 $\mathrm{mJ}$ to $2000 \mathrm{~mJ}$. Irradiation was followed by a development in deionized water during $60 \mathrm{~s}$. For DA of $35 \%$, no patterns could be obtained in the bioresist whatever the applied dose. On the contrary, low DA chitosan films appeared of interest as we can see on the Figure 11.
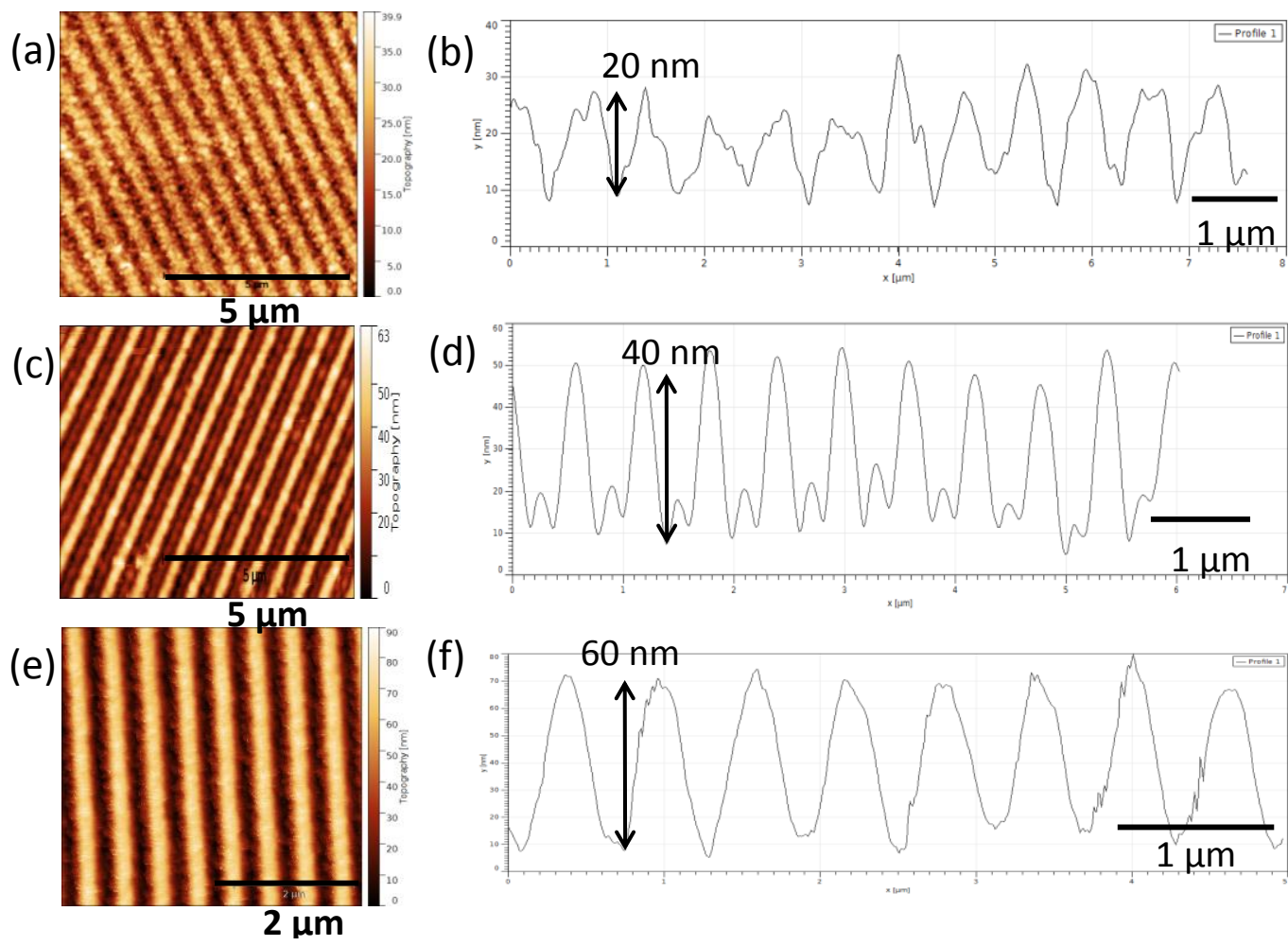

Figure 11 : AFM images and profiles of patterns obtained in a chitosan bioresist film after photolithography at $193 \mathrm{~nm}$ and development in deionized water for $1 \mathrm{~min}$ for (a, b) $300 \mathrm{~mJ}$, (c,d) $500 \mathrm{~mJ}$ and (e, f) $1000 \mathrm{~mJ}$.

On Figure 11, patterns appeared for doses superior to $300 \mathrm{~mJ}$ (Figure $11 \mathrm{a}$ and b). The dose was however too low to reveal patterns on the total thickness of the film. By increasing it steadily, reproduction of patterns was of better quality

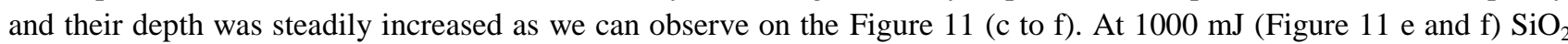
layer was almost reached, the film thickness of chitosan was of $90 \mathrm{~nm}$. Profile of the patterns was sinusoidal suggesting that the chitosan resist has a linear response under deep UV exposure instead of a binary one. Interestingly, the dose needed to pattern the chitosan bioresist is in the same order of magnitude to standard photoresists used in the same setup.

These first results need to be optimized and the photochemical pathway is still under investigation but they are promising for the use of chitosan bioresist for $193 \mathrm{~nm}$.

\subsection{Transfer by etching}

In several applications and particularly in microelectronics, lithography is followed by a step of transfer. We studied the transfer by reactive ion etching by $\mathrm{CHF}_{3}$ plasma. 
Transfer into silica by $\mathrm{CHF}_{3}$ plasma etching during 4 min and stripping by $\mathrm{O}_{2}$ plasma for 2 min were applied on chitosan and chitosan - riboflavin films after lithography. Previously, we assessed the chitosan selectivity at $4.25^{19}$. In the Figure 12 , examples of patterns after transfer and stripping after photolithography are also displayed.
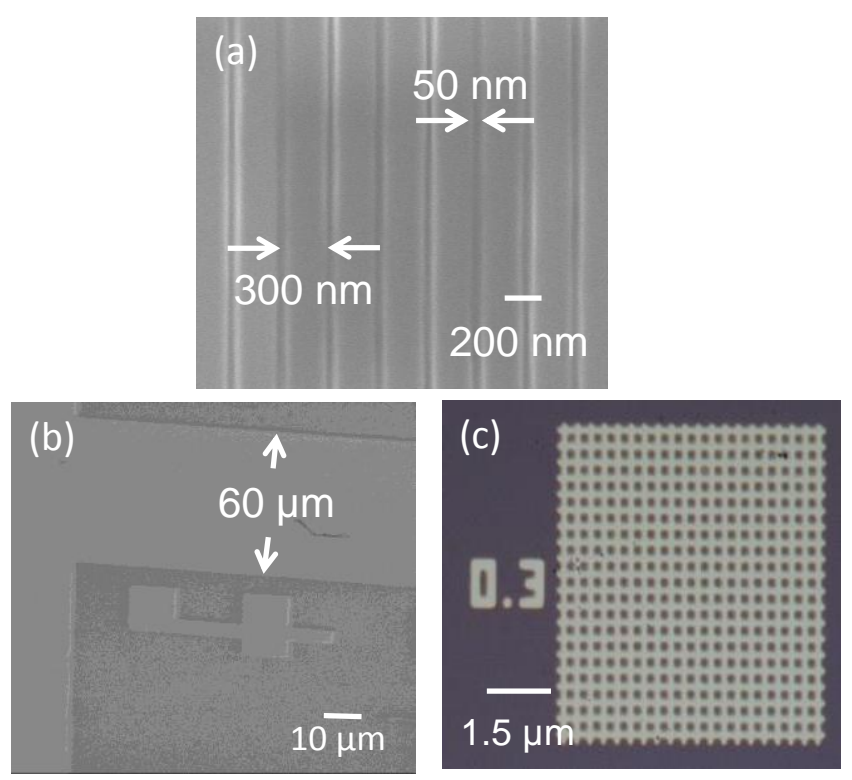

Figure 12 : SEM images of patterns after transfer by reactive ion etching of $\mathrm{CHF}_{3}$ plasma and stripping by $\mathrm{O}_{2}$ plasma obtained (a) by e-beam lithography $(30 \mathrm{kV}) 50 \mathrm{~nm}$ lines spaced by $300 \mathrm{~nm}$ from Caillau et al. ${ }^{19}$ and by photolithography at $248 \mathrm{~nm}\left(10800 \mathrm{~mJ} . \mathrm{cm}^{-2}\right)$ (b) $60 \mu \mathrm{m}$ lines and (c) optical image of $0.3 \mu \mathrm{m}$ patterns $\left(6400 \mathrm{~mJ} . \mathrm{cm}^{-2}\right)$.

In Figure 12 a, were displayed the patterns obtained by $30 \mathrm{kV}$ e-beam lithography after transfer and stripping from a chitosan DA $2 \%$ film. We noticed that even for high resoluted patterns obtained by e-beam lithography was of high quality with very low line edge roughness of only $5 \mathrm{~nm}^{19}$. In photolithography, the transfer was also successfully done for chitosan DA $35 \%$ - riboflavin films as shown in the Figure $12 \mathrm{~b}$ for photolithography at $248 \mathrm{~nm}$. The size was still well respected with squares of $(436 \pm 5) \mu \mathrm{m}$ and width of the lines of $(60 \pm 1) \mu \mathrm{m}$. Figure $12 \mathrm{c}$ displays that such quality of transfer was also reached for sub-micronic resoluted mask patterns in photolithography.

It was demonstrated that addition of riboflavin to chitosan did not impair the selectivity of the chitosan allowing for the transfer of the patterns by $\mathrm{CHF}_{3}$ plasma. Therefore, these experimental results open the possibility of using chitosan as a resist for e-beam lithography and photolithography followed by fluorinated gas plasma etching.

\section{CONCLUSIONS}

Aiming at developing green resist for lithography, a biopolymer, chitosan, issued from waste repurposing was proposed for a complete lithography and etching process. In addition, no chemical modification of chitosan nor any oil-based and toxic chemical were necessary.

Only water was used as a solvent. We also demonstrated that chitosan is a ubiquitous positive tone resist allowing for ebeam lithography at $30 \mathrm{kV}$ and $100 \mathrm{kV}$ as well as photolithography at 193 and $248 \mathrm{~nm}$. In the latter case, a natural, water soluble, non-toxic photoactivator was needed: riboflavin. We showed that the DA affect the effectiveness of the riboflavin promoted reaction. 
Next works will focus on the increase of sensitivity for UV lithography particularly at $248 \mathrm{~nm}$.

\section{ACKNOWLEDGEMENTS}

Nanolyon platform is acknowledged for equipment and support. Thierry Chevolleau and Christophe Lemonias from the Plateforme Technologique Amont of Grenoble are acknowledged for access, equipment and technical support. Green lithography project is supported by Pulsalys. EEA doctoral school is acknowledged for the doctoral scholarship for Mathieu Caillau.

\section{REFERENCES}

[1] Clark, J. H., "Green chemistry: challenges and opportunities," Green Chem. 1(1), 1-8 (1999).

[2] Anastas, P. T. and Kirchhoff, M. M., "Origins, Current Status, and Future Challenges of Green,” Acc. Chem. Res. 35(9), 686-694 (2002).

[3] Karn, B., "The road to green nanotechnology,” J. Ind. Ecol. 12(3), 263-266 (2008).

[4] Smith, G. B., "Green nanotechnology," Proc. SPIE 810402 (2011).

[5] Levinson, H. J., "Lithography - Green and getting greener," Jpn. J. Appl. Phys. 50(6 part 2), 06GA01 (2011).

[6] Takei, S., Oshima, A., Sekiguchi, A., Yanamori, N., Kashiwakura, M., Kozawa, T. and Tagawa, S., "Electron beam lithography using highly sensitive negative type of plant-based resist material derived from biomass on hardmask layer," Appl. Phys. Express 4(10), 106502 (2011).

[7] Takei, S., Oshima, A., Wakabayashi, T., Kozawa, T. and Tagawa, S., "Eco-friendly electron beam lithography using waterdevelopable resist material derived from biomass," Appl. Phys. Lett. 101(3), 33106 (2012).

[8] Takei, S., Oshima, A., Ichikawa, T., Sekiguchi, A., Kashiwakura, M., Kozawa, T., Tagawa, S., Oyama, T. G., Ito, S. and Miyasaka, H., "Organic solvent-free water-developable sugar resist material derived from biomass in green lithography," Microelectron. Eng. 122, 70-76 (2014).

[9] Takei, S., Oshima, A., Oyama, T. G., Ito, K., Sugahara, K., Kashiwakura, M., Kozawa, T., Tagawa, S. and Hanabata, M., "Application of natural linear polysaccharide to green resist polymers for electron beam and extreme-ultraviolet lithography," Jpn. J. Appl. Phys. 53(11) (2014).

[10] Kim, S., Marelli, B., Brenckle, M. A., Mitropoulos, A. N., Gil, E.-S., Tsioris, K., Tao, H., Kaplan, D. L. and Omenetto, F. G., "All-water-based electron-beam lithography using silk as a resist.," Nat. Nanotechnol. 9(4), 306-310 (2014).

[11] Park, J., Lee, S.-G., Marelli, B., Lee, M., Kim, T., Oh, H.-K., Jeon, H., Omenetto, F. G. and Kim, S., "Eco-friendly photolithography using water-developable pure silk fibroin," RSC Adv. 6(45), 39330-39334 (2016).

[12] Jiang, B., Yang, J., Li, C., Zhang, L., Zhang, X. and Yang, P., "Water-Based Photo- and Electron-Beam Lithography Using Egg White as a Resist," Adv. Mater. Interfaces 4(7), 1601223 (2017).

[13] Rinaudo, M., "Chitin and chitosan: Properties and applications," Prog. Polym. Sci. 31(7), 603-632 (2006).

[14] Park, I., Cheng, J., Pisano, A. P., Lee, E. S. and Jeong, J. H., "Low temperature, low pressure nanoimprinting of chitosan as a biomaterial for bionanotechnology applications," Appl. Phys. Lett. 90(2007), 32-35 (2007).

[15] Fernandez, J. G., Mills, C. A., Martinez, E., Lopez-Bosque, M. J., Sisquella, X., Errachid, A. and Samitier, J., "Micro- and nanostructuring of freestanding, biodegradable, thin sheets of chitosan via soft lithography," J. Biomed. Mater. Res. - Part A 85(1), 242-247 (2008).

[16] Cheng, J. C., Cauley, T. H. and Pisano, A. P., "Lithographic patterning of immobilized enzymes in chitosan thin films for multi-layer, chemical/biological sensors," Proc. 7th IEEE, 334-337 (2007).

[17] Voznesenskiy, S., Nepomnyaschiy, A. and Kulchin, Y., "Study of Biopolymer Chitosan as Resist for Submicron Electronic Lithography," Solid State Phenom. 213, 180-185 (2014).

[18] Voznesenskiy, S. and Nepomnyaschiy, A., "Dose Characteristics of Multilayer Chitosan-Metal-Dielectric Nanostructures for Electronic Nanolithography," Solid State Phenom. 245, 195-199 (2015).

[19] Caillau, M., Laurenceau, E., Chevolot, Y., Leclercq, J., Alekseev, S., Chevalier, C. and Delair, T., "Fifty nanometer lines patterned into silica using water developable chitosan bioresist and electron beam lithography," J. Vac. Sci. Technol. B, Nanotechnol. Microelectron. Mater. Process. Meas. Phenom. 35(6), 06GE01 (2017).

[20] Laskowski, J. S., Liu, Q. and O'Connor, C. T., "Current understanding of the mechanism of polysaccharide adsorption at the mineral/aqueous solution interface,” Int. J. Miner. Process. 84(1-4), 59-68 (2007).

[21] Nosal, W. H., Thompson, D. W., Yan, L., Sarkar, S., Subramanian, A. and Woollam, J. A., "UV-vis-infrared optical and AFM study of spin-cast chitosan films," Colloids Surfaces B Biointerfaces 43(3-4), 131-137 (2005).

[22] Sheraz, M. A., Kazi, S. H., Ahmed, S., Anwar, Z. and Ahmad, I., "Photo, thermal and chemical degradation of riboflavin," Beilstein J. Org. Chem. 10, 1999-2012 (2014). 
[23] Demain, A. L., "Riboflavin oversynthesis,” Annu. Rev. Microbiol. 26, 369-388 (1972).

[24] Escalada, J. P., Pajares, A., Gianotti, J., Biasutti, A., Criado, S., Molina, P., Massad, W., Amat-Guerri, F. and García, N. A., "Photosensitized degradation in water of the phenolic pesticides bromoxynil and dichlorophen in the presence of riboflavin, as a model of their natural photodecomposition in the environment," J. Hazard. Mater. 186(1), 466-472 (2011).

[25] Emslie, A. G., Bonner, F. T. and Peck, L. G., "Flow of a Viscous Liquid on a Rotating Disk," J. Appl. Phys. 29(5), 858-862 (1958).

[26] Flory, P. J., “Thermodynamics of High Polymer Solutions,” J. Chem. Phys. 10(1), 51-61 (1942).

[27] Rinaudo, M., Milas, M. and Dung, P. Le., "Characterization of chitosan. Influence of ionic strength and degree of acetylation on chain expansion,” Int. J. Biol. Macromol. 15(5), 281-285 (1993).

[28] Anthonsen, M. W., Vårum, K. M. and Smidsrød, O., "Solution properties of chitosans: conformation and chain stiffness of chitosans with different degrees of N-acetylation," Carbohydr. Polym. 22(3), 193-201 (1993).

[29] Wang, W. and Xu, D., "Viscosity and flow properties of concentrated solutions of chitosan with different degrees of deacetylation,” Int. J. Biol. Macromol. 16(3), 149-152 (1994).

[30] Urbánek, M., Kolařík, V., Krátký, S., Matějka, M., Horáček, M. and Chlumská, J., "Monte Carlo Simulation of Proximity Effect in E-Beam Lithography,” NANOCON 2013 - Conf. Proceedings, 5th Int. Conf., 723-726 (2013).

[31] Sionkowska, A., Wisniewski, M., Skopinska, J., Vicini, S. and Marsano, E., "The influence of UV irradiation on the mechanical properties of chitosan/poly(vinyl pyrrolidone) blends," Polym. Degrad. Stab. 88(2), 261-267 (2005).

[32] Wasikiewicz, J. M., Yoshii, F., Nagasawa, N., Wach, R. A. and Mitomo, H., "Degradation of chitosan and sodium alginate by gamma radiation, sonochemical and ultraviolet methods," Radiat. Phys. Chem. 73(5), 287-295 (2005)

[33] Sionkowska, A., Kaczmarek, H., Wisniewski, M., Skopinska, J., Lazare, S. and Tokarev, V., "The influence of UV irradiation on the surface of chitosan films," Surf. Sci. 600(18), 3775-3779 (2006).

[34] Pajares, A., Gianotti, J., Stettler, G., Bertolotti, S., Criado, S., Posadaz, A., Amat-guerri, F. and García, N. A., "Modelling the natural photodegradation of water contaminants A kinetic study on the light-induced aerobic interactions between riboflavin and 4-hydroxypyridine," J. Photochem. Photobiol. A Chem. 139(2-3), 199-204 (2001).

[35] Amerik, Y. and Guillet, J. E., "The Photochemistry of Ketone Polymers. IV. Photolysis of Methyl Vinyl Ketone Copolymers," Macromolecules 4(4), 375-379 (1971).

[36] Kubota, N. and Eguchi, Y., "Facile Preparation of Water-Soluble N-Acetylated Chitosan and Molecular Weight Dependence of Its Water-Solubility.," Polym. J. 29(2), 123-127 (1997).

[37] Won-Seok Choi, Kị-Jin Ahn, Dong-Wook-Lee, M.-W. B., "Preparation of chitosan oligomers by irradiation,” Polym. Degrad. Stab. 78(3), 533-538 (2002). 